\title{
KUALITAS HIDUP POPULASI NORMAL DI KOTA YOGYAKARTA MENGGUNAKAN KUISIONER SF-36
}

\section{QUALITY OF LIFE OF NORM POPULATION IN YOGYAKARTA CITY USING THE QUESTIONNAIRE SF-36}

\author{
Wahid Sabaan, Dyah A. Perwitasari \\ Fakultas Farmasi Universitas Ahmad Dahlan Yogyakarta \\ Email: Wahid08201@gmail.com
}

\begin{abstract}
ABSTRAK
Kualitas hidup yang baik ditemukan pada seseorang yang dapat menjalankan fungsi dan perannya dalam kehidupan sehari-hari dengan baik, sesuai tahap perkembangannya di masyarakat. Kondisi sosial budaya di Daerah Istimewa Yogyakarta antara lain meliputi kependudukan, tenaga kerja, transmigrasi, kesejahteraan sosial, kesehatan, pendidikan, kebudayaan, dan keagamaan yang berbeda-beda. Hal ini yang mengakibatkan perbedaan kualitas hidup di setiap masyarakat. Penelitian ini bertujuan untuk mengetahui kualitas hidup pada populasi normal di kota Yogyakarta, dan pengaruh karakteristik masyarakat terhadap kualitas hidup pada populasi normal di kota Yogyakarta. Penelitian ini menggunakan jenis penelitian observasional analitik dengan pendekatan Crosssectional, pengambilan sampel secara purposiv pada populasi normal di kota Yogyakarta yang memenuhi kriteria inklusi. Instrumen penelitian mengunakan kuesioner SF-36. Analisis data menggunakan analisis univariat, bivariat, dan multivariate. Penelitian ini diikuti oleh 400 orang. Hasil penelitian menunjukkan nilai rerata domain kualitas hidup SF-36 adalah fungsi fisik 91,21 ( $\mathrm{SD}=12,09)$, peranan fisik 84,18 $(\mathrm{SD}=29,05)$, keterbatasan peranan emosi 84,04 $(\mathrm{SD}=29,84)$, fatiguel vitalitas 69,43 ( $\mathrm{SD}=16,14)$, kesehatan mental 75,20 ( $\mathrm{SD}=15,35)$, fungsi sosial 73,11 ( $S D=20,71)$, nyeri 76,79 ( $S D=18,31)$, dan kesehatan umum 71,69 $(\mathrm{SD}=12,18)$. Terdapat perbedaan yang signifikan $(\mathrm{p}<0,05)$ pada kualitas hidup berdasarkan usia, jenis kelamin, pekerjaan, penghasilan, status pernikahan pada kuisioner SF-36. Terdapat hubungan signifikan antara karakteristik (usia, pendidikan, pekerjaan, penghasilan, status pernikahan) dengan kualitas hidup. Berdasarkan pengukuran kusioner SF-36 menunjukkan domain fungsi fisik dipengaruhi oleh usia; domain keterbatasan peran emosi, dan kesehatan mental, dipengaruhi karakteristik status pernikahan. Terdapat hubungan dan pengaruh karakteristik masyarakat terhadap kualitas hidup populasi normal di kota Yogyakarta.
\end{abstract}

Kata kunci : populasi normal, kualitas hidup, kuisioner SF-36. 


\section{ABSTRACT}

A good quality of life be observed in someone who can do role and function in the society everyday. Culture and society conditions in Yogyakarta city among others, include population, employment, resettlement, social welfare, health, education, culture, and religion are different. This resulting difference in quality of life in every community. This study was aimed to measure the quality of life population norm city of Yogyakarta, and effect of characteristics to the quality of live at norm population in Yogyakarta City. This study was carried out using analytical observational types of research with cross-sectional approach, the sample was retrieved purposive of normal population in the city of Yogyakarta who was fulfilled the inclusion criteria. The research instruments used questionnaire SF-36. Data analysis was conducted using univariate, bivariate, and multivariate. In total, 400 people were participated in the study. The result of this study showed average count of SF-36 quality of life was the physic function 91.21 (SD=12.09), the limitation of physics function $84.18(S D=29.05)$, the limitation of emotional function $84.04(S D=29.84)$, the vitality $69.43(S D=16.14)$, mental health 75.20 (SD=15.35), social function 73.11 (SD=20.71), pain 76.79 $(S D=18.31)$ and general health $71.69(S D=12.18)$. This study showed significant $(p<0.05)$ in the quality of life by age, gender, occupation, income, marital status on the SF-36 questionnaire. This study showed correlation between characteristic (age, occupation, income, marriage status) with quality of life. According to the SF-36, age may affect physical functioning; marriage status may affect role limitations due to emotional problems \& emotional well being. Our study find correlation between society characteristics and quality of live of norm population in Yogyakarta City.

Keyword: normal population, quality of life, the questionnaire SF-36

\section{PENDAHULUAN}

Pembangunan kesehatan diarahkan untuk meningkatkan kesadaran, kemauan, dan kemampuan hidup sehat bagi setiap orang agar peningkatan derajat kesehatan masyarakat yang setinggi-tingginya dapat terwujud (Anonim, 2010). Kualitas hidup yang baik ditemukan pada seseorang yang dapat menjalankan fungsi dan perannya dalam kehidupan sehari-hari dengan baik, sesuai tahap perkembangannya. "Kualitas hidup individu dapat dilihat dari lima hal, yaitu produktivitas kerja, kapabilitas intelektual, stabilitas emosi, perannya dalam kehidupan sosial, serta ditunjukkan dengan adanya kepuasan hidup yang baik dari segi materi maupun non-materi” (Renwick et al., 1996).

Pencapaian kualitas hidup yang baik tidaklah mudah, dengan adanya perbedaan itu ikut mempengaruhi kualitas hidup pada beberapa kelompok 
masyarakat (Primardi dan Hadjam, 2011). Kota Yogyakarta adalah salah satu kota kuno di Indonesia. Kota Yogyakarta adalah ibukota propinsi Daerah Istimewa Yogyakarta, dan dikenal luas sebagai kota budaya, kota pelajar, kota sejarah/ perjuangan dan kota pariwisata. Kondisi sosial budaya di Daerah Istimewa Yogyakarta antara lain meliputi kependudukan, tenaga kerja, transmigrasi, kesejahteraan sosial, kesehatan, pendidikan, kebudayaan, dan keagamaan yang berbeda-beda. Hal ini yang mengakibatkan perbedaan kualitas hidup di setiap masyarakat (Adrisijanti, 2007; Kemendagri, 2013; Anonim, 2016).

Penelitian kualitas hidup pada populasi normal di beberapa negara telah dilakukan. Namun penelitian kualitas hidup pada populasi normal masih kurang dilakukan di Indonesia. Maka dari itu, dalam kesempatan ini akan dicoba untuk mengevaluasi kualitas hidup masyarakat pada populasi normal di kota Yogyakarta, diharapkan dengan adanya penelitian kualitas hidup pada populasi normal yang diukur dengan kuisioner SF-36 dapat menjadi acuan dalam penelitian lain yang berhubungan dengan kualitas hidup.

\section{METODE PENELITIAN}

Penelitian ini adalah observasional analitik dengan metode cross sectional. Desain penelitian tersebut efektif digunakan untuk memperoleh dan membandingkan data antar variabel pada waktu yang sama dengan prosedur yang sederhana. Penelitian dilakukan selama 3 bulan pada periode Maret-Juni 2015. Responden yang memenuhi kriteria inklusi kemudian diminta persetujuannya untuk terlibat dalam penelitian dengan mengisi inform consent. Penelitian ini sudah mendapatkan persetujuan dari komite etik penelitian Universitas Ahmad Dahlan (KEP UAD) dengan no persetujuan etik (Ethical Approval) $=011504041$.

\section{A. Kriteria Inklusi}

Orang yang menyatakan diri sehat yang tidak sedang menderita penyakit berat sehingga perlu perawatan di rumah sakit, usia 17-55 tahun, berdomisili di kota Yogyakarta, responden masih kooperatif, responden bersedia menjadi subyek penelitian dengan menjalani kegiatan sebagaimana disampaikan dalam lembar informed consent. 


\section{B. Kriteria Ekslusi}

Orang yang tidak sehat jiwa maupun fisik, sementara mendapat perawatan pihak medis di rumah sakit atau puskesmas. Pasien mengisi kuesioner secara tidak jelas.

C. Perhitungan Sampel

Untuk jumlah subjek penelitian dapat digunakan rumus Slovi (Setiawan, 2007), dimana populasi masyarakat kota Yogyakarta 428.282 jiwa.

$$
\begin{aligned}
& \qquad \mathrm{n}=\mathrm{N} /(1+\mathrm{Ne} 2) \\
& \mathrm{n}= \text { Number of samples (jumlah sampel) } \\
& \mathrm{N}= \text { Total population (jumlah seluruh anggota populasi) } \\
& \mathrm{E}= \text { Error tolerance (toleransi terjadinya galat; taraf signifikansi; untuk } \\
&\text { sosial dan pendidikan lazimnya } 0,05) \\
& \mathrm{N}= 428.282 \text { Jiwa } \\
& \mathrm{e}= 0,05 \\
& \mathrm{n}= 28.282 /[1+(428.282 \times 0,05 \times 0,05) \\
& \mathrm{n}= 399,62 \approx 400 \text { sampel }
\end{aligned}
$$

\section{HASIL DAN PEMBAHASAN}

\section{A. Data Demografi Karakteristik Responden}

Gambaran karakteristik penelitian yang dilakukan pada 400 responden dapat ditunjukan dengan jumlah dan persentase. Persentase usia (18-40 Tahun) $87,8 \%$, dan usia (41-64 tahun) 12,3\%. Persentase laki-laki 44,8\%, dan perempuan $55,3 \%$. Persentase pendidikan rendah (buta huruf, tidak tamat SD, tamatan SD, tamatan SMP) 13,5\%, dan pendidikan tinggi (tamatan SMA/SMK, tamatan Akademi, tamatan S1, tamatan S2/S3/Sederajat) 86,5\%. Persentase yang tidak bekerja 59,3\%, dan yang bekerja (wiraswasta, pegawai swasta, pegawai negeri/ABRI) 40,8\%. Persentase penghasilan perbulan di bawah 2 juta 77,0\%, dan persentase penghasilan di atas 2 juta 23,0\%. Persentase yang belum menikah $79,5 \%$, dan yang sudah menikah 20,5\%. Gambaran karakteristik penelitian pada populasi normal di kota Yogyakata dapat dilihat pada Tabel I. 
Tabel I. Data karakteristik penelitian pada populasi normal di kota Yogyakarta

\begin{tabular}{lcc}
\hline Kategori / karakteristik penelitian & Jumlah $(\mathbf{n}=\mathbf{4 0 0})$ & Persentase (\%) \\
\hline Usia : & 351 & $87,8 \%$ \\
a. 18-40 Tahun & 49 & $12,3 \%$ \\
b. 41-64 Tahun & $25,93 \pm 8,75$ Tahun \\
\hline Rerata Usia \pm Standar Deviasi & 179 & $44,8 \%$ \\
\hline Jenis kelamin : & 221 & $55,3 \%$ \\
a. Laki-laki & & \\
b. Perempuan & 54 & $13,5 \%$ \\
\hline Pendidikan & 346 & $86,5 \%$ \\
a. Rendah & & \\
b. Tinggi & 237 & $59,3 \%$ \\
\hline Pekerjaan : & 163 & $40,8 \%$ \\
a. Tidak Bekerja & & \\
b. Bekerja & 308 & $77,0 \%$ \\
\hline Penghasilan : & 92 & $23,0 \%$ \\
a. < Juta & & \\
b. > Juta & 318 & $79,5 \%$ \\
\hline Status Pernikahan & 82 & $20,5 \%$ \\
a. Belum Menikah & & \\
b. Sudah Menikah &
\end{tabular}

B. Pengukuran Kualitas Hidup Berdasarkan Kuisiner SF-36

Tabel II. Distribusi rerata kuesioner SF-36 dan peneliti lain

\begin{tabular}{|c|c|c|c|c|c|c|c|}
\hline \multirow{3}{*}{$\begin{array}{l}\text { Domain } \\
\text { Kuesione } \\
\text { r SF-36 }\end{array}$} & \multirow{2}{*}{\multicolumn{2}{|c|}{$\begin{array}{l}\text { Populasi Normal di } \\
\text { kota Yogyakarta } \\
(\mathbf{N}=\mathbf{4 0 0})\end{array}$}} & \multirow{2}{*}{\multicolumn{2}{|c|}{$\begin{array}{c}\begin{array}{c}\text { Populasi Normal di } \\
\text { China** }\end{array} \\
(\mathbf{N}=\mathbf{2 4 1 0})\end{array}$}} & \multirow{2}{*}{\multicolumn{2}{|c|}{$\begin{array}{c}\begin{array}{c}\text { Populasi Normal di } \\
\text { India** }\end{array} \\
(\mathbf{N}=\mathbf{1 8 4})\end{array}$}} & \multirow{3}{*}{$p$} \\
\hline & & & & & & & \\
\hline & Mean & SD & Mean & SD & Mean & SD & \\
\hline FF & 91,21 & 12,09 & 91,83 & 12,89 & 93,59 & 14,34 & 0,1137 \\
\hline PF & 84,18 & 29,05 & 90,44 & 17,93 & 78,53 & 35,37 & $0,000^{*}$ \\
\hline PE & 84,08 & 29,84 & 87,67 & 18,16 & 79,89 & 35,71 & $0,000^{*}$ \\
\hline V & 69,43 & 16,14 & 59,92 & 18,36 & 80,82 & 19,22 & $0,000^{*}$ \\
\hline KM & 75,20 & 15,35 & 71,46 & 16,67 & 86,16 & 14,92 & $0,000 *$ \\
\hline FS & 73,11 & 20,71 & 91,19 & 16,57 & 90,82 & 17,70 & $0,000^{*}$ \\
\hline $\mathrm{N}$ & 76,79 & 18,31 & 83,98 & 21,89 & 83,80 & 26,98 & $0,000^{*}$ \\
\hline KU & 71,69 & 12,18 & 55,98 & 20,18 & 79,41 & 20,42 & $0,000 *$ \\
\hline
\end{tabular}


Berdasarkan distribusi rerata kuisioner SF-36, dan peneliti (Lam et al., 2013) di China, dan (Sinha et al., 2013) di Negara India, terdapat perbedaan yang signifikan $(p<0,05)$ pada 7 domain, peranan fisik, keterbatasan peran emosi, vitalitas, kesehatan mental, fungsi sosial, nyeri dan kesehatan umum. Pada domain fungsi fisik tidak ditemukan perbedaan yang signifikan, sehingga kualitas hidup hampir sama dengan peneliti di China dan India. Distribusi rerata kuesioner SF-36 dan peneliti lain dapat dilihat pada Tabel II.

C. Pengukuran Kualitas Hidup Berdasarkan Karakteristik Masyarakat

Pengukuran kualitas hidup berdasarkan karakteristik masyarakat dapat dilihat pada Tabel III. Perbedaan yang signifikan $(\mathrm{p}<0,05)$ diperoleh dari kualitas hidup pada populasi normal di kota Yogyakarta, berdasarkan usia terdapat pada domain peran fisik, keterbatasan peranan emosi, kesehatan mental, kesehatan umum. Berdasarkan jenis kelamin terdapat pada domain fungsi fisik. Berdasarkan status pekerjaan terdapat pada domain kesehatan mental. Berdasarkan penghasilan terdapat pada keterbatasan peranan emosi, kesehatan mental, nyeri. Berdasarkan status pernikahan terdapat pada domain keterbatasan peranan emosi, vitalitas. Pengukuran kualitas hidup berdasarkan pendidikan tidak ditemukan perbedaan yang signifikan (nilai $\mathrm{p}<0,05$ ). 
Tabel III. Perbedaan kualitas hidup pada populasi normal berdasarkan karateristik masyarakat

\begin{tabular}{|c|c|c|c|c|c|c|c|c|c|c|c|c|c|}
\hline \multirow{4}{*}{ Domain } & \multirow{4}{*}{ Nilai } & \multicolumn{12}{|c|}{ Kuesioner SF-36 } \\
\hline & & \multicolumn{2}{|c|}{ Usia } & \multicolumn{2}{|c|}{ Jenis Kelamin } & \multicolumn{2}{|c|}{ Pendidikan } & \multicolumn{2}{|c|}{ Pekerjaan } & \multicolumn{2}{|c|}{ Penghasilan } & \multicolumn{2}{|c|}{ Status Pernikahan } \\
\hline & & $18-40$ & 41-64 & Laki-laki & Perempuan & Tinggi & Rendah & Tidak bekerja & Bekerja & $<2$ Juta & $>2$ Juta & Belum Nikah & Sudah Nikah \\
\hline & & $(\mathrm{N}=351)$ & $(\mathrm{N}=49)$ & $(\mathrm{N}=179)$ & $(\mathrm{N}=221)$ & $(\mathrm{N}=\mathbf{5 4})$ & $(\mathrm{N}=346)$ & $(\mathrm{N}=\mathbf{2 3 7})$ & $(\mathrm{N}=163)$ & $(\mathrm{N}=308)$ & $(\mathrm{N}=92)$ & $(\mathrm{N}=318)$ & $(\mathrm{N}=82)$ \\
\hline \multirow{3}{*}{$\begin{array}{l}\text { Fungsi } \\
\text { Fisik }\end{array}$} & Mean & 91,75 & 87,35 & 92,45 & 90,20 & 88,61 & 91,61 & 91,35 & 91,01 & 91,02 & 91,84 & 91,81 & 88,90 \\
\hline & $\mathrm{SD}$ & 11,8 & 13,03 & 10,94 & 12,88 & 13,57 & 11,61 & 10,98 & 13,57 & 11,69 & 13,37 & 11,60 & 30,04 \\
\hline & $P$ & \multicolumn{2}{|c|}{$0,017^{*}$} & \multicolumn{2}{|c|}{$0,041 *$} & \multicolumn{2}{|c|}{0,131} & \multicolumn{2}{|c|}{0,361} & \multicolumn{2}{|c|}{0,149} & \multicolumn{2}{|c|}{0,114} \\
\hline \multirow{3}{*}{$\begin{array}{l}\text { Peranan } \\
\text { Fisik }\end{array}$} & Mean & 83,35 & 88,77 & 84,35 & 84,09 & 86,57 & 83,81 & 84,81 & 83,28 & 83,27 & 87,22 & 84,66 & 82,31 \\
\hline & SD & 29,96 & 21,08 & 28,65 & 29,43 & 27,77 & 29,27 & 29,13 & 29,00 & 29,73 & 26,59 & 28,82 & 30,04 \\
\hline & $P$ & \multicolumn{2}{|c|}{0,618} & \multicolumn{2}{|c|}{0,850} & \multicolumn{2}{|c|}{0,400} & \multicolumn{2}{|c|}{0,324} & \multicolumn{2}{|c|}{0,206} & \multicolumn{2}{|c|}{0,336} \\
\hline \multirow{3}{*}{$\begin{array}{l}\text { Ketetebatasan } \\
\text { Peran } \\
\text { Emosi }\end{array}$} & Mean & 82,62 & 94,55 & 83,61 & 84,46 & 85,80 & 83,81 & 82,98 & 85,68 & 82,46 & 89,49 & 81,97 & 92,27 \\
\hline & $\mathrm{SD}$ & 30,94 & 17,14 & 30,67 & 29,21 & 27,92 & 30,15 & 31,23 & 27,70 & 30,95 & 25,16 & 31,60 & 19,80 \\
\hline & $P$ & \multicolumn{2}{|c|}{$0,005^{*}$} & \multicolumn{2}{|c|}{0,901} & \multicolumn{2}{|c|}{0,750} & \multicolumn{2}{|c|}{0,506} & & & 0,00 & \\
\hline Vitalitas & Mean & 69,18 & 71,22 & 70,42 & 68,94 & 67,12 & 69,79 & 68,37 & 70,98 & 68,60 & 72,23 & 68,67 & 72,37 \\
\hline Vitalitas & $\mathrm{SD}$ & 15,10 & 17,36 & 17,16 & 15,21 & 16,95 & 16,01 & 15,96 & 16,32 & 15,88 & 16,76 & 15,88 & 16,87 \\
\hline & $P$ & 0,3 & & & 246 & 0,2 & & 0,14 & & & & 0,0 & \\
\hline Kesehatan & Mean & 74,33 & 81,47 & 76,35 & 74,28 & 72,64 & 73,98 & 73,59 & 77,54 & 74,12 & 75,77 & 74,00 & 79,85 \\
\hline Mental & $\mathrm{SD}$ & 15,39 & 14,06 & 16,59 & 14,32 & 15,72 & 15,32 & 15,24 & 15,37 & 15,45 & 14,72 & 15,43 & 14,42 \\
\hline & $P$ & 0,0 & & & 979 & 0,2 & & 0,010 & & & & 0,0 & \\
\hline Fungsi & Mean & 73,27 & 71,94 & 71,78 & 74,18 & 72,31 & 73,23 & 74,54 & 71,02 & 73,16 & 72.93 & 73,95 & 69,84 \\
\hline Sosial & SD & 20,49 & 22,39 & 21,64 & 19,90 & 20,90 & 20,71 & 20,32 & 21,15 & 20,85 & 20,34 & 20,61 & 20,88 \\
\hline & $P$ & 0,6 & & & 162 & 0,8 & & 0,08 & & & & 0,0 & \\
\hline Nyeri & Mean & 77,36 & 72,70 & 77,30 & 76,38 & 73,84 & 77,23 & 76,97 & 76,53 & 75,82 & 80,02 & 77,25 & 75,00 \\
\hline Nyerı & $\mathrm{SD}$ & 17,64 & 22,34 & 17,94 & 18,64 & 19,31 & 18,14 & 17,97 & 18,87 & 18,25 & 18,25 & 17,71 & 20,50 \\
\hline & $P$ & 0,2 & & & 738 & 0,2 & & 0,81 & & & & 0,5 & \\
\hline Kesehatan & Mean & 71,26 & 74,79 & 71,90 & 71,52 & 70,74 & 71,84 & 71,35 & 72,20 & 71,20 & 73,35 & 71,28 & 73,30 \\
\hline Umum & SD & 12,18 & 11,99 & 12,27 & 12,14 & 11,46 & 12,30 & 12,09 & 12,33 & 11,99 & 12,75 & 12,05 & 12,63 \\
\hline & $P$ & 0,0 & $31 *$ & & 843 & 0,4 & & 0,43 & & & & 0,0 & \\
\hline
\end{tabular}

Keterangan *Mann-Whitney signifikansi $p<0,05$ 
D. Pengaruh Karakteristik Kualitas Hidup Berdasarkan Kuisioner SF-36

Untuk melihat pengaruh kerakteristik terhadap kulitas hidup dapat dilihat pada Tabel IV. Pada analisis korelasi Spermen dan asosiasi ETA ditemukan adanya perbedaan yang signifikan (nilai $\mathrm{p}<0,05$ ), domain fungsi fisik terhadap karakteristik usia, jenis kelamin, pendidikan dan status pernikahan, domain keterbatasan peran emosi terhadap karakteristik usia, penghasilan dan status pernikahan, domain vitalitas terhadap karakteristik usia, pekerjaan dan status pernikahan, domain kesehatan mental terhadap karakteristik usia, jenis kelamin, pendidikan, pekerjaan, penghasilan, dan status pernikahan, domain nyeri terhadap terhadap karakteristik usia, pendidikan dan penghasilan, domain kesehatan umum, terhadap karakteristik usia, penghasilan dan status pernikahan. Untuk melihat pengaruh karakteristik terhadap kulitas hidup dilakukan uji regresi linear berganda yang terlihat pada Tabel IV.

Tabel IV.Hasil analisis regresi linear berganda karakteristik populasi normal di kota Yogyakarta terhadap kualitas hidup (SF-36)

\begin{tabular}{|c|c|c|c|c|c|c|c|}
\hline \multirow{2}{*}{ Domain } & \multirow{2}{*}{ Model } & \multicolumn{2}{|c|}{ Coefficients } & \multicolumn{2}{|c|}{ Excluded variable } & \multicolumn{2}{|c|}{ ANOVA } \\
\hline & & Beta & Sign & Beta In & Sign & $\mathbf{F}$ & Sign \\
\hline \multirow{4}{*}{$\begin{array}{l}\text { Fungsi } \\
\text { Fisik }\end{array}$} & Usia & $-0,120$ & 0,017 & - & - & \multirow{4}{*}{5,775} & \multirow{4}{*}{0,017} \\
\hline & $\begin{array}{c}\text { Jenis } \\
\text { Kelamin }\end{array}$ & - & - & $-0,101$ & 0,043 & & \\
\hline & Pendidikan & - & - & 0,058 & 0,256 & & \\
\hline & $\begin{array}{c}\text { Status } \\
\text { Pernikahan }\end{array}$ & - & - & $-0,035$ & 0,593 & & \\
\hline \multirow{3}{*}{$\begin{array}{l}\text { Peranan } \\
\text { Emosi }\end{array}$} & Usia & - & - & 0,071 & 0,273 & \multirow{3}{*}{7,909} & \multirow{3}{*}{0,005} \\
\hline & Penghasilan & - & - & 0,058 & 0,269 & & \\
\hline & $\begin{array}{c}\text { Status } \\
\text { Pernikahan }\end{array}$ & 0,140 & 0,005 & - & - & & \\
\hline \multirow{6}{*}{$\begin{array}{l}\text { Kesehatan } \\
\text { Mental }\end{array}$} & Usia & - & - & 0,091 & 0,158 & \multirow{6}{*}{9,594} & \multirow{6}{*}{0,002} \\
\hline & $\begin{array}{c}\text { Jenis } \\
\text { Kelamin }\end{array}$ & - & - & $-0,055$ & 0,266 & & \\
\hline & Pendidikan & - & - & 0,090 & 0,073 & & \\
\hline & Pekerjaan & - & - & 0,073 & 0,184 & & \\
\hline & Penghasilan & - & - & 0,086 & 0,101 & & \\
\hline & $\begin{array}{c}\text { Status } \\
\text { Pernikahan }\end{array}$ & 0,153 & 0,002 & - & - & & \\
\hline
\end{tabular}


Hasil analisis pada domain fungsi fisik menunjukkan nilai signifikan pada karakteristik usia, maka dapat dikatakan variabel karakteristik usia signifikan menjadi prediktor fungsi fisik. Karakteristik jenis kelamin, pendidikan dan status pernikahan variabel pada penelitian ini dikeluarkan dari analisis. Melihat hasil analisis multivariat tersebut dapat disimpulkan bahwa usia merupakan faktor dominan yang simultan dapat mempengaruhi domain fungsi fisik responden populasi normal terhadap kualitas hidupnya.

Domain peranan emosi menunjukkan nilai signifikan pada karakteristik status pernikahan, maka dapat dikatakan variabel karakteristik status pernikahan signifikan menjadi prediktor keterbatasan peran emosi. Karakteristik usia dan penghasilan merupakan variabel yang dikeluarkan dari analisis. Melihat hasil analisis multivariat tersebut dapat disimpulkan bahwa status pernikahan merupakan faktor dominan yang simultan dapat mempengaruhi domain keterbatasan peran emosi responden populasi normal terhadap kualitas hidupnya.

Domain kesehatan mental menunjukkan nilai signifikan pada karakteristik status pernikahan, maka dapat dikatakan variabel karakteristik status pernikahan signifikan menjadi prediktor kesehatan mental. Karakteristik usia, jenis kelamin, pendidikan, pekerjaan dan penghasilan merupakan variabel yang dikeluarkan dari analisis. Melihat hasil analisis multivariat tersebut dapat disimpulkan bahwa status pernikahan merupakan faktor dominan yang simultan dapat mempengaruhi domain kesehatan mental responden populasi normal terhadap kualitas hidupnya.

Pada domain vitalitas, fungsi sosial, nyeri dan kesehatan umum, semua karakteristik tidak dapat mempengaruhi, domain tersebut. Berdasarkan penjelasan di atas maka domain fungsi fisik, kesehatan mental dan kesehatan umum dipengaruhi oleh usia, berbeda pada domain keterbatasan peran emosi, karakteristik status pernikahan mempengaruhi kulitas hidup. Penelitian kualitas hidup pada populasi normal yang dilakukan (Montazeri et al., 2005) di Iraq (Sinha et al., 2013) dan India fungsi fisik dan kesehatan mental dipengaruhi oleh karakteristik usia. 


\section{KESIMPULAN}

Hasil evaluasi kualitas hidup menggunakan kuesioner SF-36 dilihat dari nilai $\mathrm{x} \pm \mathrm{SD}$, kualitas hidup pada populasi normal di kota Yogyakarta adalah domain fungsi fisik 91,21 ( $\mathrm{SD}=12,09)$, peranan fisik 84,18 ( $\mathrm{SD}=29,05)$, keterbatasan peranan emosi 84,04 ( $\mathrm{SD}=29,84)$, fatiguel vitalitas 69,43 $(\mathrm{SD}=16,14)$, kesehatan mental 75,20 ( $\mathrm{SD}=15,35)$, fungsi sosial 73,11 ( $\mathrm{SD}=20,71)$, nyeri 76,79 ( $\mathrm{SD}=18,31)$ dan kesehatan umum 71,69 $(\mathrm{SD}=12,18)$.

Perbedaan signifikan diperoleh dari kualitas hidup pada populasi normal di kota Yogyakarta; mengunakan kuisioner SF-36, berdasarkan usia terdapat pada domain peran fisik, keterbatasan peranan emosi, kesehatan mental dan kesehatan umum. Berdasarkan jenis kelamin, terdapat pada domain fungsi fisik. Berdasarkan status pekerjaan terdapat pada domain kesehatan mental. Berdasarkan penghasilan, terdapat pada domain keterbatasan peranan emosi, kesehatan mental, nyeri. Berdasarkan status pernikahan, terdapat pada domain keterbatasan peranan emosi, vitalitas.

Pengaruh karakteristik masyarakat terhadap kualitas hidup pada populasi normal di kota Yogyakarta berdasarkan pengukuran menggunakan kuisioner SF36, menunjukan perbedaan yang signifikan yaitu: pada domain fungsi fisik, yang dipengaruhi oleh usia; domain keterbatasan peran emosi, dan kesehatan mental yang dipengaruhi karakteristik status pernikahan.

\section{DAFTAR PUSTAKA}

Adrisijanti, I., 2007, Kota Yogyakarta sebagai Kawasan Pusaka Budaya Potensi dan Permasalahannya. Disajikan dalam Diskusi Sejarah "Kota dan Perubahan Sosial dalam Perspektif Sejarah", diselenggarakan oleh Balai Pelestarian Sejarah dan Nilai Tradisional, Yogyakarta, Jurusan Arkeolog Fakultas Ilmu Budaya Universitas Gajah Mada.

Anonim, 2010, Rencana Stategis Kementrian Kesehatan Tahun 2010-2014, Jakarta.

Anonim, 2016, Daerah Istimewa Yogyakarta, diakses 17 Januari, 2017, dari https://id.wikipedia.org/wiki/Daerah_Istimewa_Yogyakarta. 
Dahlan, M.S., 2014, Statistik untuk kedokteran dan kesehatan: Deskriptif, Bivariat, dan Multivariat ed 6, Epidemiologi Indonesia.

Jogjaku, 2012, Kehidupan Sehari-Hari, diakses tanggal 26 November, 2014, dari http://www.yogyakartatourism.com/tourism-info/kehidupan-sehari-hari/.

Kemendagri, 2013, Provinsi D.I. Yogyakarta, diakses tanggal 22 November, 2014, dari http://www.kemendagri.go.id/pages/profil-daerah/provinsi/detail/ 34/di-yogyakarta.

Lam, E.T., Lam, C. L., Fong, D.Y., dan Huang, W.W., 2013, Is the SF-12 version 2 Health Survey a valid and equivalent substitute for the SF-36 version 2, Health Survey for the Chinese, Journal of evaluation in clinical practice, 19 (1): 200-208.

Montazeri, A., Goshtasebi, A., Vahdaninia M., dan Gandek, B., 2005, The Short Form Health Survey (SF-36): translation and validation study of the Iranian version, Quality of Life Research, 14 (3): 875-882.

Primardi, A. dan Hadjam, M.N.R., 2011, Optimisme, harapan, dukungan sosial keluarga, dan kualitas hidup orang dengan epilepsi, Jurnal Ilmiah Psikologi, 3 (2): 124.

Renwick, R., Brown, I., dan Nagler, M., 1996, Quality of Life in Health Promotion and Rehabilitation: Conceptual Approaches, Issues, and Applications, Sage Publications, 437.

Setiawan, N., 2007, Penentuan Ukuran Sampel Memakai Rumus Slovin dan Tabel Krejcie-Morgan: Telaah Konsep dan Aplikasinya, Diskusi Ilmiah, Jurusan Sosial Ekonomi Fakultas Peternakan Unpad, Bandung, Fakultas Peternakan Universitas Padjadjaran, Kamis 22 November 2007.

Sinha, R., W. J. van den Heuvel dan P. Arokiasamy, 2013, Validity and reliability of MOS short form health survey (SF-36) for use in India, Indian Journal of Community Medicine, 38 (1): 22. 